\title{
Structural correction of nonlinear dynamics of frequency- controlled induction motor drives
}

Vladimir L. Kodkin, Aleksandr S. Anikin, Aleksandr A. Baldenkov

Departement of theoretical fundamentals of electrical engineering, South Ural State University, Russia

\begin{tabular}{|c|c|}
\hline Article Info & ABSTRACT \\
\hline Article history: & \multirow{10}{*}{$\begin{array}{l}\text { Frequency analysis of processes in the frequency-controlled induction motor } \\
\text { drive s, as in automatic control systems with dynamic non-linearities, are } \\
\text { presented in this paper. For the first time, the dynamic transfer function in } \\
\text { terms of electromagnetic torque }(\mathrm{m}) \text { from absolute slip determined by the } \\
\text { load and frequency of the supply voltage are proposed. To study the dynamic } \\
\text { characteristics, a method for constructing a family of frequency } \\
\text { characteristics for fixed values of absolute slipss and frequencies of the } \\
\text { supply voltage are described. The frequency characteristics corresponding to } \\
\text { these transfer functions are constructed in the Simulink application of the } \\
\text { MatLab software. Based on results of the analysis the structural correction } \\
\text { methods that improve the dynamics of such nonlinear systems are proposed. } \\
\text { This paper is an example of how the initial complicated (but more accurate) } \\
\text { interpretation of nonlinearity allowed us to find a new best solution to the } \\
\text { problem of controlling a complex dynamic object. }\end{array}$} \\
\hline Received Jul 7, 2019 & \\
\hline Revised Aug 12, 2019 & \\
\hline Accepted Nov 18, 2019 & \\
\hline Keywords: & \\
\hline Dynamic positive feedback & \\
\hline Frequency analysis & \\
\hline Frequency response & \\
\hline Induction motor drive & \\
\hline Nonlinear dynamic & \\
\hline
\end{tabular}

Structural correction

This is an open access article under the CC BY-SA license.

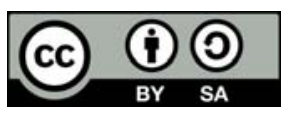

\section{Corresponding Author:}

Aleksandr S. Anikin, Departement of Theoretical fundamentals of electrical engineering, South Ural State University, 76, Lenin prospekt, Chelyabinsk, Russia. 454080

Email: anikinas@susu.ru

\section{INTRODUCTION}

The widespread use of frequency converters for controlling asynchronous motors in recent years has created the impression that there are no problems in the field of induction motor drive (IMD). However, the results of studies [1-5] show that the dynamic characteristics of these systems require a more in-depth study from the point of view of the theory of control of nonlinear systems. Frequency controlled IMDs are a highly non-linear system. The "main" parameter determining the non-linearity of these systems is the variable frequency of the supply voltage. Unlike the stationary non-linearities of the regulatory systems considered in the 80 s and 90 s of the 20th century, the variable frequency in the IMD changes its frequency response.

Variable frequency, strictly speaking, does not allow the use of a mathematical apparatus designed for IMDs, based on vector analysis, since the vector representation of variables over time implies the constancy of the frequency of the supply voltage, or the frequency of rotation of these vectors. However, due to the absence of another, vector methods are used in most research or educational works on IMDs [6-8], despite the fact that the authors quite often recognize the illegality of such an approach.

\section{PROBLEM STATEMENT}

The most effective engineering method for assessing the dynamics of electric drives is the method of frequency analysis [9-11]. Direct application of this method to IMDs is hampered by the presence of 
significant non-linearities in them. The construction of the frequency characteristics of such systems involves a number of inevitable assumptions [12-15]. After considering the different versions of these assumptions, the calculation of the dynamic mechanical characteristic set forth in the Usoltsev's monograph [12] turned out to be the most acceptable. The calculation is repelled by equation 1.36 on p.23 [12]. It establishes a connection between the current moment $(m)$ and $\operatorname{slip}(\beta)$ at the nominal frequency $\omega_{1 \text { nom: }}$ :

$$
m=\frac{2 M_{k}}{\left(1+T_{2} \prime p\right)\left[\frac{S_{k}}{\beta}\left(1+T_{2}^{\prime} p\right)\right]+\frac{\beta}{S_{k}}}
$$

Where, $T_{2}^{\prime}=\frac{L_{k}}{R_{2}}-$ the transient time constant of the rotor, $\beta=\frac{\omega_{2}}{\omega_{1}}-$ the relative slip, $M_{k}-$ the critical moment, $S_{k}-$ the critical slip at the nominal frequency $\omega_{1 \text { ном. }}$

At the beginning of the working characteristic (for $M \approx 0, \beta \geq 0$ ), the transfer function is simplified and reduces to a dynamic link of the 1 st order:

$$
m=\frac{2 M_{k}}{\left(1+T_{2} \prime p\right) \frac{S_{k}}{\beta}}=\frac{2 M_{k} \beta}{\left(1+T_{2} \prime p\right) S_{k}}=\frac{2 M_{k}\left(\omega_{1}-\omega\right)}{\left(1+T_{2} \prime p\right) S_{k} \omega_{1}}
$$

To determine the transfer function by the electromagnetic torque $(m)$ from absolute slip $(\Delta \omega=$ $\left.\omega_{1}-\omega\right)$, we transform it to the form:

$$
W_{\mathrm{D}}(p)=\frac{m}{\Delta \omega}=\frac{2 M_{k}}{\left(1+T_{2} \prime p\right) S_{k} \omega_{1}}
$$

However, the results of experiments given in $[1,16]$ showed that it is incorrect to extend this formula to all operating modes.

\section{SOLUTION}

The expression (1) allowed us to propose another variant of linearization, in which the initial equation takes the form:

$$
m\left[\left(T_{2}{ }^{\prime}\right)^{2} p^{2}+2 T_{2}^{\prime} p+1+\left(\frac{\beta}{S_{K}}\right)^{2}\right]=\frac{2 M_{k}}{S_{k}} \beta\left(1+T_{2}^{\prime} p\right)
$$

In this case, expression (1), the binding torque $(m)$, relative slip $(\beta)$, and quantities determined by the parameters of the electric motor $\left(T_{2}^{\prime}\right.$ - transition time constant; $M_{k}, s_{k}$ - critical moment and critical slip, depending on the frequency $\omega_{1}$ ) will be transformed to:

$$
m=\frac{2 M_{k}\left(T_{2}^{\prime} p+1\right) S_{k} \beta}{\left(1+T_{2} \prime p\right)^{2} S_{k}^{2}+\beta^{2}}
$$

and the transfer function (2) will be represented as follows:

$$
W(p)=\frac{2 M_{k}\left(T_{2}^{\prime} p+1\right) S_{k}}{\omega_{1}\left[\left(1+T_{2}^{\prime} p\right)^{2} S_{k}^{2}+\beta^{2}\right]}
$$

where $\omega_{1}-$ the stator supply voltage frequency.

The working section (at $0 \leq m \leq 2 M_{r}$, where $M_{r}$ is the rated torque) of the mechanical characteristics of the IMD will be described by the structural diagram shown in Figure 1.

Equation (3) appears to be substantially nonlinear, since it will transform when the frequency of the supply voltage and slip of the motor change. Formula (4) can be called the dynamic Kloss formula $(M=$ $\left.\frac{2 \cdot M_{k}}{\frac{S}{S_{\mathrm{Kp}}}+\frac{S_{\mathrm{Kp}}}{S}}\right)$. The formulas become identical when substituted into the formula (4) $p=0$, i.e. for a static state. For $\beta=0$, i.e. without load, formula (4) coincides with the formula given in the Usoltsev monograph [12]. These changing properties of the transfer function determine the change in the dynamics of IMD with frequency control, noted earlier in experiments. Thus, the "freezing" of the transfer functions is effective enough to interpret the dynamic characteristics of IMD. 


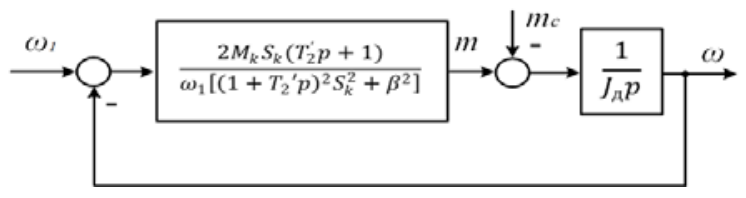

Figure 1. Block diagram of IMD with the working section of the mechanical characteristics

Figures $2 \mathrm{a}$ and $2 \mathrm{~b}$ below show the frequency characteristics of IMD based on a low-power motor $(0.37 \mathrm{~kW})$ with a squirrel-cage rotor. To build frequency characteristics, hereinafter, the software package Simulink MatLab was used. The given amplitude and phase-frequency characteristics of the motor for the frequencies of the stator voltage of $10 \mathrm{~Hz}$ (Figure 2a) and $50 \mathrm{~Hz}$ (Figure 2b) correspond to slips at low $\left(0.2 M_{r}\right)-\mathrm{W} 1$ and rated load $\left(M_{r}\right)-\mathrm{W} 2$.

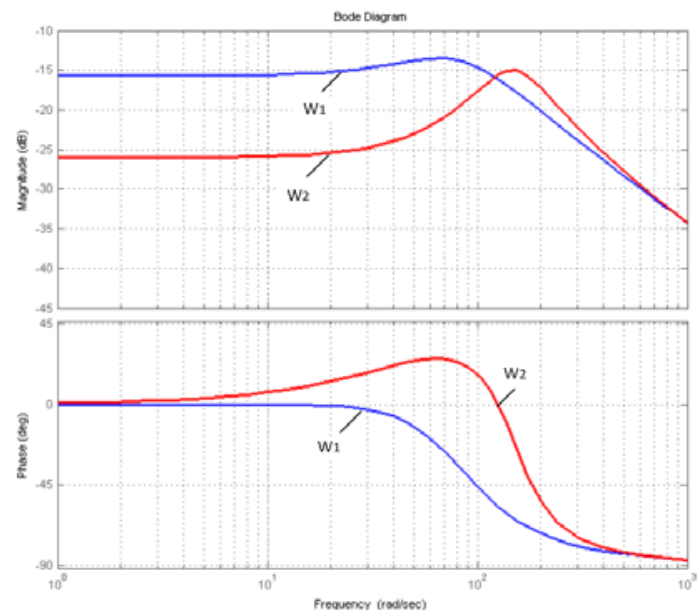

(a)

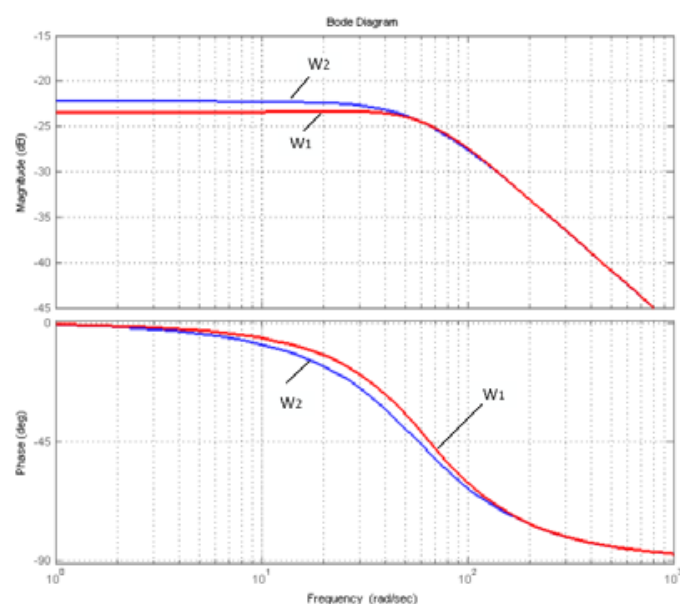

(b)

Figure 2. The amplitude and phase characteristics of the IMD at a frequency of the stator supply voltage of 10 (a) 50 (b) $H z$ : W1 - slip at a load torque of $0.2 M_{r}$, W2 - slip at a load torque of $M_{r}$

The given frequency responses well explain some problems of AC drive. Figure $2 \mathrm{a}$ shows that at a stator supply voltage frequency of $10 \mathrm{~Hz}$ and a small load, the phase shifts of the frequency response (W1) in the range from 10 to $100 \mathrm{rad} / \mathrm{s}$ vary from 40 to -90 degrees. Comparison of frequency responses at frequencies of stator voltage of 10 and $50 \mathrm{~Hz}$ shows that in the range from 10 to $100 \mathrm{rad} / \mathrm{s}$ the phase shifts of frequency responses have significantly different values - from 25 to -45 electric degree. This means that during acceleration and deceleration, the phase shifts change in such a way that a system with a stability margin at a frequency of $50 \mathrm{~Hz}$ can become unstable. The frequency of the stator voltage will be $10 \mathrm{~Hz}$. This may be the reason for the different oscillation of the drive at different frequencies of the stator voltage, which were noted in $[17,18]$. Thus, the nonlinearities of the transfer functions of the link of the torque generator Figure 1 require linearization to increase the efficiency of the electric drive and the same behavior at different frequencies.

Most often, "transvector" control is used to linearize the IMD. With this control, dynamic links are formed in the control device that are inverse, mainly, to the inertia of the rotor circuits, with the rotor speed adapting to the frequency of the stator voltage, however, this does not take into account the pulsed nature of the frequency converter and the presence of other harmonic components in the rotor and stator currents (except fundamental harmonic) [19-24].

Another factor that significantly worsens the operation of vector control should be recognized that a number of parameters (for example, stator and rotor resistances) can change significantly during operation,

Int J Pow Elec \& Dri Syst Vol. 11, No. 1, Mar 2020 : 220-227 
and it is almost impossible to track these changes. All this contributes to the nonlinearity of the rotor and stator currents during vector control and leads to a significant decrease in its efficiency $[1,4,16]$.

Consider an alternative linearization of the transfer function $W_{D}$ with respect to the electromagnetic torque (5). For this, in the structural diagram [25], we introduce local feedback (Figure 3 ) on the electromagnetic torque with the transfer function $W_{D P F}$ (the introduced designation will be explained below).

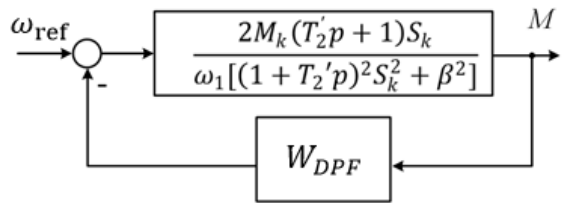

Figure 3. Introduction of feedback $W_{D P F}$

We determine the transfer function $W_{\text {eqv }}$ by the electromagnetic torque:

$$
W_{\text {eqv }}=\frac{\frac{2 M_{k}\left(T_{2}^{\prime} p+1\right) S_{k}}{\omega_{1}\left[\left(1+T_{2} \prime p\right)^{2} S_{k}^{2}+\beta^{2}\right]}}{1+\frac{2 M_{k} S_{k}\left(T_{2}^{\prime} p+1\right) W_{D P F}}{\omega_{1}\left[\left(1+T_{2} \prime p\right)^{2} S_{k}^{2}+\beta^{2}\right]}}=\frac{2 M_{k} S_{k}\left(T_{2}^{\prime} p+1\right)}{\omega_{1}\left[\left(1+T_{2} \prime p\right)^{2} S_{k}^{2}+\beta^{2}\right]+2 M_{k} S_{k}\left(T_{2}^{\prime} p+1\right) W_{D P F}}
$$

Under the following condition:

$$
\omega_{1} \beta^{2}=-2 M_{k} S_{k}\left(T_{2}^{\prime} p+1\right) W_{D P F}
$$

That is, if the corrective element will have the following transfer function:

$$
W_{D P F}=-\frac{\omega_{1} \beta^{2}}{2 M_{k} S_{k}\left(T_{2}^{\prime} p+1\right)}
$$

Then the transfer function $W_{\text {eqv }}$ by the electromagnetic torque looks like:

$$
W_{\mathrm{eqv}}=\frac{2 M_{k} S_{k}\left(T_{2}^{\prime} p+1\right)}{\omega_{1}\left[\left(1+T_{2} \prime p\right)^{2} S_{k}^{2}\right]}=\frac{2 M_{k}}{\omega_{1} S_{k}\left(1+T_{2}^{\prime} p\right)}
$$

When this condition is fulfilled, the transfer function $W_{\text {eqv }}$ with respect to the electromagnetic torque will completely coincide with expression (2) given in [12].

Expression (6) for the link $W_{D P F}$ has the form of an aperiodic link of the first kind, the gain of which in the final form depends on the frequency of the stator supply voltage and on absolute slip. A negative sign in front of the fraction indicates that the proposed corrective relationship should be positive. Based on this, the designation DPF - dynamic positive feedback was introduced above. In modern drives, it is quite simple to realize the necessary dependence of the coefficient on the frequency of the voltage of the electric motor.

The selection of feedback coefficients according to condition (6) makes it possible to obtain a linearized transfer function of an asynchronous electric motor at any frequency of the supply voltage and load. Such a transfer function, on the one hand, becomes identical to the previously known formula for the transfer function of an asynchronous drive at zero slip (i.e., without load), and, on the other hand, to the wellknown Kloss formula for static modes of operation of an asynchronous motor.

The next step shows an example of determining the coefficients of the corrective link at frequencies of the supply voltage of 10 and $50 \mathrm{~Hz}$ for two types of loads $0.2 M_{r}$ and $M_{r}$. The calculation results of the transfer functions of the torque driver of the initial IMD and the corrective link are presented in Table 1. The resulting amplitude and phase characteristics are combined with the corresponding characteristics without introducing the corrective link (Figure $2 \mathrm{a}$ and $2 \mathrm{~b}$ ) and are presented in Figure 4 and Figure 5, respectively.

In widely used IMDs, it is very difficult to realize the link by mechanical torque. Given that the torque is equal to $I_{1} \cdot \psi_{2}$ and in almost all calculations it is assumed that the rotor flux linkage is constant, you can replace the original signal in this local connection with the effective value of the stator current, or its active component, which is calculated in all frequency converters. 


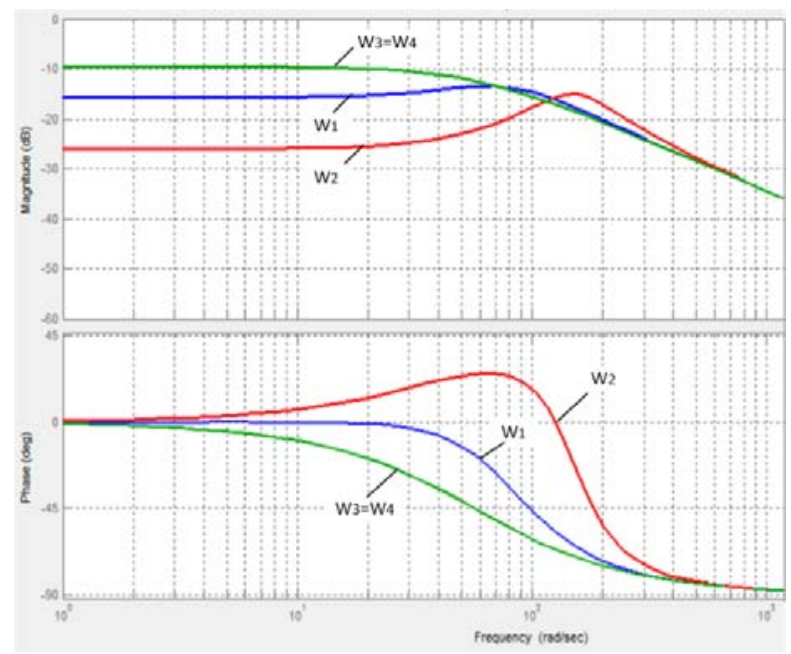

Figure 4. The amplitude and phase characteristics of the IMD at a frequency of the stator supply voltage of $10 \mathrm{~Hz}$ : W1 and W2 - slip at a load moment of $0.2 M_{r}$ and $M_{r}$ without correction, W3 and W4 - slip at a load moment of $0.2 M_{r}$ and $M_{r}$ with the introduction of $W_{D P F}$

Table 1. The transfer functions of the torque driver of the initial IMD and the corrective element

\begin{tabular}{|c|c|c|c|}
\hline & * & $W_{I M D}(p)$ & $W_{D P}$ \\
\hline \multirow{3}{*}{$10 \mathrm{~Hz}$} & & $0,038 p+0,226$ & 0,707 \\
\hline & $p_{1}$ & $\begin{array}{c}\overline{0,0002 p^{2}+0,0229 p+1,38} \\
0,038 p+0,226\end{array}$ & $\begin{array}{c}0,0038 p+0,226 \\
3,84\end{array}$ \\
\hline & $\beta_{2}$ & $\begin{array}{c}\overline{0,0002 p^{2}+0,0229 p+4,52} \\
0,027 p+1,548\end{array}$ & $\begin{array}{c}\overline{0,0038 p+0,226} \\
0,141\end{array}$ \\
\hline \multirow[t]{2}{*}{$50 \mathrm{~Hz}$} & $\beta_{1}$ & $\begin{array}{c}\overline{0,006 p^{2}+0,628 p+20,56} \\
0,027 p+1,548\end{array}$ & $\begin{array}{c}\overline{0,27 p+1,548} \\
0,77\end{array}$ \\
\hline & $\beta_{2}$ & $\overline{0,006 p^{2}+0,628 p+21,19}$ & $\overline{0,27 p+1,548}$ \\
\hline
\end{tabular}

* $\beta_{1}$ - absolute slip at $0.2 M_{r}, \beta_{2}-$ absolute slip at $M_{r}$

For stator current feedback, the linearization condition will vary slightly:

$$
\omega_{1} \beta^{2}=-2 M_{k} S_{k}\left(T_{2}^{\prime} p+1\right) \frac{W_{D P F}}{\Psi_{2}}
$$

From this equality it follows that the high accuracy of the IMD can be obtained by regulating the flow of the rotor, while correcting the linearization conditions.

However, if there is a permissible design error in determining the parameters of the $W_{D P F}$ link, i.e.

$$
\frac{\beta}{S_{k}}-\frac{2 M_{k}\left(T_{2}^{\prime} p+1\right) \cdot W_{1}}{\Psi_{2}} \neq 0=\Delta
$$

the amplitude and phase characteristics of the IMD will be similar to the characteristics of a linear link of the first kind. 


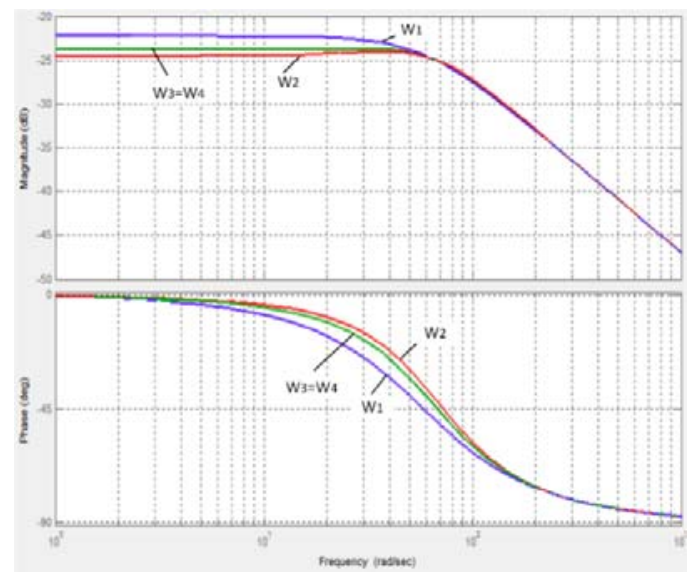

Figure 5. The amplitude and phase characteristics of the IMD at a frequency of the stator supply voltage of $50 \mathrm{~Hz}$ : W1 and W2 - slip at a load moment of $0.2 M_{r}$ and $M_{r}$ without correction, W3 and W4 - slip at a load moment of $0.2 M_{r}$ and $M_{r}$ with the introduction of $W_{D P F}$

In the last part of the article, the influence of the accuracy of the selection of $W_{D P F}$ link parameters on the operation of the IMD is investigated. For this, a transmission coefficient error of $\pm 5 \%$ was introduced. According to the obtained frequency characteristics, the drive remains stable both at a supply voltage frequency of $10 \mathrm{~Hz}$ (Figure 6) and at $50 \mathrm{~Hz}$ (Figure 7).

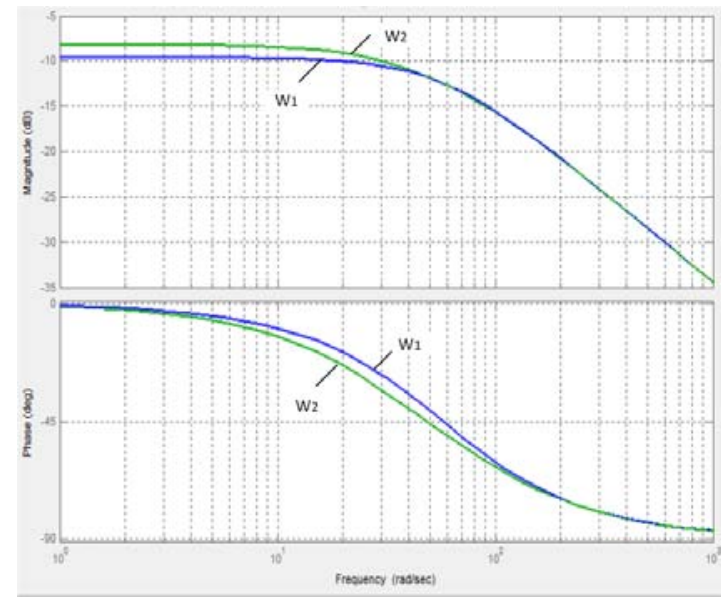

$$
\begin{aligned}
& W_{\mathrm{DPF}} 1=\frac{3,84}{0,0038 p+0,226} \\
& W_{\mathrm{DPF}} 2=\frac{4}{0,0038 p+0,226}
\end{aligned}
$$

Figure 6. The amplitude and phase characteristics of the IMD at a frequency of the stator supply voltage of $10 \mathrm{~Hz}$ : W1 - accurate, W2 - when the transmission coefficient of the correction link deviates by $5 \%$ 


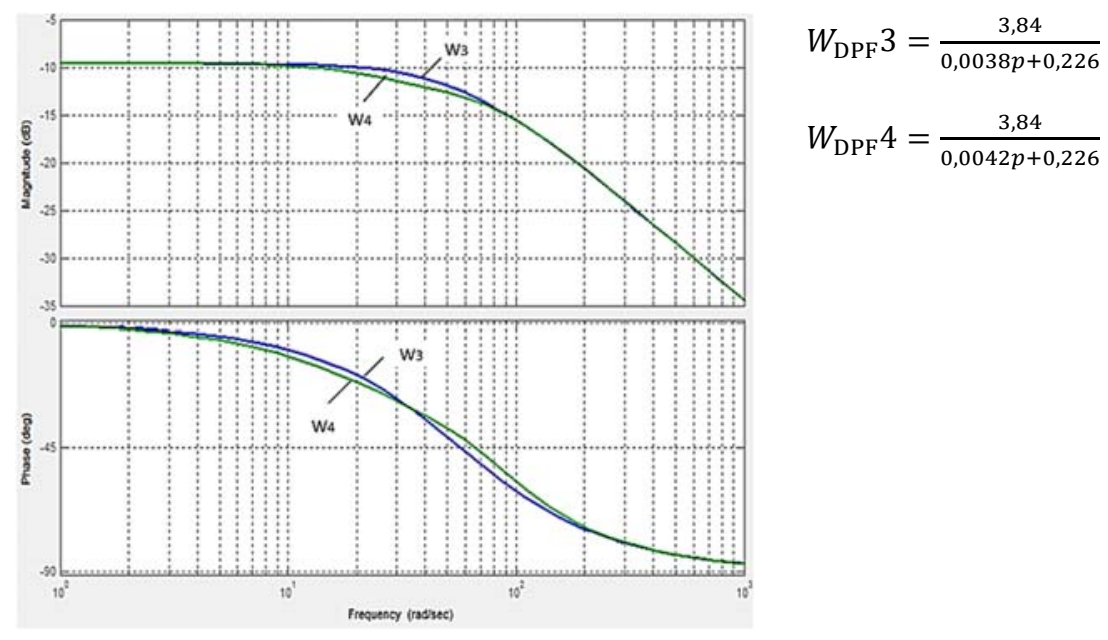

Figure 7. The amplitude and phase characteristics of the IMD at a frequency of the stator supply voltage of $50 \mathrm{~Hz}$ : W1 - accurate, W2 - when the transmission coefficient of the correction link deviates by 5\%

\section{CONCLUSIONS}

In the presented article, the transfer function of the torque former in frequency-controlled IMD $\mathrm{s}$ was first proposed. This transfer function takes into account the frequency of stator voltage and slip. Such a formula, on the one hand, becomes identical to the previously known formula for the transfer function of an asynchronous drive at zero slip (i.e., without load), and, on the other hand, to the well-known Kloss formula for static modes of operation of an asynchronous motor.

The frequency characteristics of the IMD, built on this transfer function, gave an adequate explanation of the changing dynamics of the drive, noted in experiments conducted earlier.

The proposed transfer function made it possible to justify the structure of effective correction (dynamic positive feedback on the stator current) for sensorless electric drives.

\section{REFERENCES}

[1] V.L. Kodkin, A.S. Anikin, A.A. Baldenkov, "The dynamics identification of asynchronous electric drives via frequency response”, International Journal of Power Electronics and Drive Systems (IJPEDS). Vol. 10 No. 1, pp. 66-73, 2019.

[2] N. A. Sukhenko, G. Ya. Pyatibratov, A. A. Danshina, L. L. "Altunyan Prospective Electromechanical Control Systems of Industrial Manipulator Efforts", International Journal of Power Electronics and Drive System (IJPEDS), Vol. 7, No. 2, pp. 416 421, June 2016.

[3] Kozyaruk A.E., Rudakov V.V., "Modern and perspective algorithmic maintenance is frequency-regulated electric drives," SPEC. Saint Petersburg, 2004.

[4] V.L. Kodkin, A.S. Anikin, A.A. Baldenkov, "Performance identification of the asynchronous electric drives by the spectrum of rotor currents," International Journal of Power Electronics and Drive Systems (IJPEDS), Vol. 10 No. 1.- P.211-218, 2019.

[5] V.L. Kodkin, A.S. Anikin, M.A. Malcher, "Problems of Implementation of Frequency Control in Mining Industry", Bulletin of the South Ural State University Series: Energy. Vol. 18, No.37, Pp. 67-71, 2012.

[6] Pozdeev, A. D., "Electromagnetic and electromechanical processes in frequency-controlled asynchronous electric drives," Cheboksary: Publishing house Chuvash University, pp. 172, 1998.

[7] Figaro B. I. Pavlyachik L. B., "Regulating electrical drives of alternating-current," Misnk: Technoperspectiva, pp. 363, 2006.

[8] Sokolovsky G. G., "Electrical drives of alternating-current with frequency controlling, “ M: Academia, pp. 267, 2006.

[9] Louis J. P., "Control of non-conventional synchronous motors," Great Britain and the United States by ISTE Ltd and John Wiley \& Sons, Inc, pp. 428, 2012.

[10] Chiasson John., "Modeling and high performance control of electric machines," John Wiley \& Sons, Inc, pp. 709, 2005.

[11] Doncker R. D, Pulle D. W. J, Veltman A., "Advanced Electrical Drives: Analysis, Modeling, Control," Advanced Electrical Drives: Analysis, Modeling, Control. Springer, pp. 474, 2011.

[12] Usoltsev A. A., "Vector control of asynchronous motors," Tutorial. - Spb .: ITMO, pp. 120, 2002.

Int J Pow Elec \& Dri Syst Vol. 11, No. 1, Mar 2020 : 220-227 
[13] Usoltsev A. A, Vorobyov N. V, Feshin B. N., "Methodology for the analysis of electromagnets of processes in subsystems of an automated electric drive," Automation and Informatics, Vol. 2, No. 35. pp. 50-53, 2014.

[14] Usoltsev A. A., "Determination of the parameters of the asynchronous motor model according to the reference data," News of universities. Instrument making, Vol. 51, No 10, pp. 35-41, 2008.

[15] Ilyina A. G, \& Usoltsev A. A., "Optimal motion control during positioning and its modeling in the MathLab," Simulink environment, Izvestiya VUZov, Instrument making, Vol. 51, No. 6. pp. 63-68, 2008.

[16] V.L. Kodkin, A.S. Anikin, A.A. Baldenkov, "Analysis of stability of electric drives as non-linear systems according to Popov criterion adjusted to amplitude and phase frequency characteristics of its elements", 2nd International Conference on Applied Mathematics, Simulation, and Modeling AMSM 2017 - Proceedings. - 2017.

[17] V.L. Kodkin, A.S. Anikin, A.A. Baldenkov. "The analysis of the quality of the frequency control of induction motor carried out on the basis of the processes in the rotor circuit" XI International Scientific and Technical Conference Dynamics of Systems, Mechanisms and Machines - Proceedings - 2017.Omsk, 14-16.11.2017.

[18] Kodkin. V.L. "Methods of optimizing the speed and accuracy of optical complex guidance systems based on equivalence of automatic control system domain of attraction and unconditional stability of their equivalent circuits," Proceedings of SPIE - The International Society for Optical Engineering. - 2016

[19] Md. Rashedul Islam, Md. Maruful Islam, Md. Kamal Hossain., "Pintu kumar sadhu performance analysis of a dtc and svm based field-orientation control induction motor drive," International Journal of Power Electronics and Drive System (IJPEDS), Vol. 5, No. 3, pp. 336-343, 2015.

[20] Hoang Le-Huy., "Modeling and simulation of electrical drives using MATLAB/Simulink and Power System Blockset," IECON'01. 27th Annual Conference of the IEEE Industrial Electronics Society, 2001.

[21] Marc Perron, \& Hoang Le-Huy, "Full load range neural network efficiency optimization of an induction motor with vector control using discontinuous PWM," IEEE International Symposium on Industrial Electronics, 2006.

[22] Hoang Le-Huy; G. Sybille MATLAB, "Simulink and PSPice as modelling tools for power systems and power electronics", 2000 Power Engineering Society Summer Meeting.

[23] Louis-A. Dessaint, \& Roger Champagne, "Real-time simulation of electric drives," Mathematics and Computers in Simulation, Vol. 63, No. 3-5, pp. 173-181, 2003.

[24] Louis-A. Dessaint, \& Kamal Al-Haddad, "Modelling and Simulation of Electric Machines, Converters and Systems," Mathematics and Computers in Simulation, Vol. 63, No. 3-5, pp. 135-143, 2003.

[25] Popov V. M., "Hyperstability of dynamic systems," Springer-Verlag, Berlin 1973. 